tainably) from the environment. So why should we attempt to conserve what is left of natural areas world-wide? For four very good reasons:

Because we don't know what we would be losing if we did not.

Because we don't know what we will need.

Because we don't know what we will want and love.

And because the world will be a less varied and much poorer place if we lose these species and their ecosystems.

From 1-10 February 1988, scientists and conservationists, policymakers and bureaucrats, gathered in San José, Costa Rica, to form policy for a new edition of the World Conservation Strategy, which was first published in 1980. The scientists were attending technical workshops that addressed the future of the International Union for Conservation of Nature and Natural Resources (IUCN). The event was the 17 th General Assembly of IUCN (the world's largest scientific conservation organization), and genetic diversity was only one of the numerous topics that were debated. Indeed much of the information presented and garnered at these Assemblies has been shown to appear only months or years later in the popular media. The 17th General Assembly of IUCN featured an opening address by the Vice-President of IUCN, HRH The Duke of Edinburgh, and another by the latest Nobel Peace Prize Winner, President Oscar Arias of Costa Rica*.

DRAKE MCHugh, IUCN Media Coordinator
World Conservation Centre
Avenue du Mont-Blanc
CH-1196 Gland
Switzerland.

* See also the more detailed account which it is hoped to publish in the Conferences \& Meetings section of our Summer issue.Ed

\title{
Ecosystem Theory and Application
}

In his recent review of the above book in this Journal (Vol. 14, No. 3, pp. 283-4), Dr Mark O. Hill focused his attention on a claimed lack of any coherent account of ecosystem theory and application, on the variety of subjects treated in 20 chapters, and on the predominant individuality of the contributions. He concluded that readers had to look elsewhere for knowing what an ecosystem really is, and for disquisitions on productivity, nutrient cycling, and trophic webs.

In this present note we would like to point out that we have experienced the book as a useful source-book and a veritable storehouse of refreshing diversity for both fieldand class-work, as well as for library purposes. There is no shortage of well-documented textbooks aimed at synthesis and enabling the student to visualize the whole. This book's main intention has been to report on the investigations into various particular questions of ecosystems theory, while still containing a significant amount of diverse practical material. It is correct that the book is directed to an audience of students, specialists, or general readers with an educated interest in the discipline of ecology. It reunites so many different perspectives on ecosystem analysis and serves to pin-point the area. We feel therefore that it is more an enlightening cross-roads book than just a collection of chapters presented to an international congress and added to subsequently by the Editor. In other words, the more the individuality, the larger the choice.
For example, the Odums' papers give comprehensive studies on ecosystems (E.P. Odum), and on systems ecology and the enmergy method (H.T. Odum). Four chapters describe various types of ecosystems. The M.J. Winterbourn one on stream ecosystems is very penetrating, provides us with useful leads, and opens up ways to other fundamental studies on the subject. In addition, one can find chapters on geobotanical descriptions, applied ecology, biospheral ethic, and macroecology from an economic perspective.

As already stated by Dr Hill, several chapters are individually first-rate syntheses. But if the book does not present a picture of the terrestrial Biosphere as an entity, the separate parts of which are linked in a dynamic way as a result of constant changes in their living components, this is not so much a shortcoming as a presentation of its stimulating diversity.

Gonzague Pillet \& Gaye Bristow Centre for Human Ecology \&

Environmental Sciences

University of Geneva

P.O. Box 266

CH 1227 Carouge-Geneva

Switzerland.

\section{Go Back for the Future to Rehabilitate Landscape}

The landscape as we know it in much of Western Europe is rapidly disappearing with the changing environmentlargely as a result of our human ignorance. The landscape is made up of everything we see: vegetation and fields, woodlands and hedgerows, rivers, lakes and ponds, plants, animal wildlife, villages, towns and cities-not forgetting far too many carelessly wasteful humans. Satisfaction of Man's needs with large-scale farming techniques, endless quarrying and mining, and the construction of seemingly new motorways, has involved the uprooting of many of our hedgerows. These formed our field and village boundaries for centuries, supporting a marvellous diversity of plant and animal life, but we wonder for how much longer they will continue to do this?

Hedgerows are now rarely replanted when damaged or destroyed, but instead are being replaced by unsightly posts and rail fencing. Admittedly, this is cheaper than replanting hedgerows; but in the long-run it is far more costly in terms of devastation of wildlife habitats and natural amenities and beauty,

Badgers (Meles taxus) are one of the species which are worst hit and are now rarely seen in the English countryside. Not only are their setts being destroyed and Badgers harmed by our urban development etc., while a lot of them are killed by cars, but they are also taken for sport such as Badger baiting. Fortunately now some farmers are getting the message and are starting to take care of their hedgerows, so that in some cases fencing has been removed and replanting of hedgerows has taken place.

In our County of Cheshire we are encouraging farmers to carry out as much replanting as possible, whether it be of hedges or trees. In some cases we actually carry out the planting free of charge, but the farmer has to agree to maintain the trees himself after the first twelve months. In most of these cases, the farmer is entitled to a Forestry or Countryside Commission grant which is very encouraging. 